Journal of Contemporary Educational Research

Research Article

\title{
Discussion on the Misconceptions of Curriculum Ideological and Political Education
}

He Zhang

Shenyang University of Technology, Shenyang 110870, Liaoning province, China

\begin{abstract}
Curriculum ideological and political education, an educational guideline that encourages the integration of ideological and political education in all subjects and courses, is being widely adopted in Chinese universities. It aims to cultivate the comprehensive abilities of students with moral, intellectual, physical, and aesthetical grounding, instead of focusing on the acquisition of knowledge only. Misconceptions of this concept are still commonly seen, however, and they are hindering the effective implementation of the guideline. This paper attempts to discuss three common misconceptions and provide insights that hopefully will clear up some confusion. Some practical approaches are also proposed in the end for teachers to follow.
\end{abstract}

Key words: Misconception; Curriculum ideological and political education; Ideological and political theory courses; Effectiveness

Publication date: October, 2020

Publication online: 31 October, 2020

*Corresponding author: He Zhang, 307960772@ qq.com

\section{Introduction}

Initially emerged in Shanghai in 2014, "curriculum ideological and political education", an initiative to integrate ideological and political education in all subjects and courses, is being carried out in Chinese universities both extensively and intensively. One important goal of such an educational guideline is to cultivate students in accordance with the national requirement and need-to produce talents with comprehensive abilities, who are not only equipped with the skills to apply the knowledge they have learned, but also critical thinking abilities, morallysound values, tradition-celebrated merits, and a broader international outlook, etc ${ }^{[1]}$. all of which help strive toward the realization of an all-rounded education. This policy, which influences, or even dictates, the quality of the future successors of this country, will have a major impact on China's destiny ${ }^{[1]}$. Important as it is, the execution is far from smooth. Misconceptions are commonly seen, and the correct interpretation of this guideline is yet to be popularized. In a way, misconceptions become the major obstacle that has been barricading the effective implementation of curriculum ideological and political education. This paper aims to discuss three common misconceptions and clear out the confusion.

\section{The Misconceptions of Curriculum Ideological and Political Education}

\subsection{Curriculum ideological and political education equals ideological and political theory courses}

"Curriculum ideological and political education" and "ideological and political theory courses" are oftentimes confused as the same due to their lexical resemblance. However, they are very different concepts in nature. Curriculum ideological and political education intends to integrate, in all subjects and majors, ideological and political education based on the knowledge of individual courses. The key is to discover "points" in these courses where ideological and political education can be applied while still focusing on the imparting of knowledge of each specific field. Ideological and political theory courses, including Marxism, socialism with Chinese characteristics, theories of Mao Zedong, 
morality education, etc., are courses that centers on the theories and practice of ideology and politics. Thus, although both concepts attempt to provide students with guidance in such areas as critical thinking, values, morality, laws, etc., the differences are also evident, mainly in three aspects:

\subsubsection{Different origins}

The ideological and political education provided by curriculum ideological and political education originates from the specialized knowledge from each specific course, be it English, engineering, material science, etc., while ideological and political theory courses usually offer such guidance based on ideological and political theories itself, with exemplifications from a variety of backgrounds. Despite of being originated from different sources, the two concepts are expected to forge strong alliance, heading toward the same direction ${ }^{[1]}$.

\subsubsection{Different intensity}

Ideological and political theory courses no doubt provide high-intensity ideological and political education, which is, after all, the sole purpose of these courses. For these courses, every section of the class is designed to teach knowledge in such areas. In comparison, the ideological and political education in curriculum ideological and political education appears only when necessary and appropriate, which means it only happens when ideological and political education can be mixed with professional knowledge in a natural and logical manner. For the parts where no ideological and political education can be associated with, it is best to leave it out. Thus, for curriculum ideological and political education, there is no hard and fast rules for the specialized courses as to how much time must be devoted to it. Instead, it is the "how" that matters.

\subsubsection{Different importance}

Among all forms of ideological and political education, ideological and political theory courses are utmost important within this genre. The theory of curriculum ideological and political education is only brought up to "assist" ideological and political theory courses, according to the educational department, to solve a detachment between ideological and political education courses and the rest of the courses, in order for them to co-function and enhance the effectiveness of ideological and political education ${ }^{[1]}$.

Hence, curriculum ideological and political education is neither a synonym nor a part of ideological and political theory courses. They are separate but also interconnected. Above all, they are not interchangeable concepts, and the confusion of them can lead to maloperation.

\subsection{Curriculum ideological and political education means forsaking the objectivity of science}

One of the concerns of curriculum ideological and political education is that many fear that teachers might have to exaggerate certain elements in terms of ideology and politics, forsaking the objectivity of sciencewhich is the golden principle for intellectuals - while doing so, thus allowing higher education to descend into narrow nationalism and nativism. This misinterpretation can be refuted from two aspects.

On the one hand, no exaggeration is encouraged in curriculum ideological and political education. What is encouraged, though, is to find the parts where materials can be added to teach students about values, morality, critical thinking skills, etc.. Therefore, this guideline is more about adding, instead of exaggerating, or even twisting. And the added information is most often objective truth, or mainstream philosophy that provide students with proper guidance. Thus, the objectivity of science stays intact even with the implementation of curriculum ideological and political education.

On the other hand, many hold the idea that classes should offer students with pure scientific knowledge, and their values, attitudes, insights are choices that should be left to the students to decide for themselves, without the interference of any teaching staff. Ideally, this could work, but the rising number of mental illness patients and offenders in colleges prove otherwise. Under the modern context of information explosion and the coexistence of varied values and cultures, young people may get easily confused, and it is wise for teachers to help them sift through the information, acquire better judgement, learn about responsibility and decency, and eventually step on the right path. The students will graduate, not only with the knowledge they have learned, but also with a sound mind and body. The requirement to educate such graduates is the new national direction, and it is natural that universities should reorient themselves to produce the workforce that the nation needs.

\subsection{Curriculum ideological and political education is adding ideological and political information in a mechanical way}

One common misunderstanding of curriculum 
ideological and political education is: this guideline requires teachers to carry out ideological and political education in a mechanical way, resembling taking a segment out of ideological and political theory courses and transplant it in specialized courses. Explanations were given in papers and official documents that, ideological and political education can be classified as explicit and implicit. Explicit ideological and political education often refers to the type that is presented in ideological and political theory courses, e.g.: introducing socialism with Chinese characteristics, traditional merits that students should uphold, etc.. Implicit ideological and political education, on the other hand, is more often featured in specialized courses, providing ideological and political education in a more subtle way, e.g. instead of listing the achievements in the field of mechanics in China, professors can introduce a theory in mechanics with the exemplification of a Chinese mechanic invention, and explain what makes it world-advanced, as a way of boosting a sense of national pride among students. Though explicit education is not exclusively used in ideological and political theory courses, and implicit education is not exclusive for curriculum ideological and political education, it is widely believed that implicit education is the best option for curriculum ideological and political education, because ideological and political education should be introduced in specialized courses without a feeling of being deliberate ${ }^{[2]}$. It should be natural and not readily noticeable. A blunt introduction of ideological and political education may be counterproductive. If mishandled, it can easily turn into preaching, which repels most, and deviate from the central task of specialized courses - to impart knowledge from each specific field.

Thus, curriculum ideological and political education is more complicated than simply adding ideological and political information in a mechanical way. It requires subtlety, which largely depends on careful teaching design.

\section{The Right Way to Approach Curriculum Ideological and Political Education}

Teachers are often referred to as the main force in the implementation of curriculum ideological and political education $^{[1]}$. Due to the fact that each course has its unique features in terms of content, teaching methods, course target, etc., no universal method can be applied in every course, and it has to rely on the teachers to provide a class design which integrates ideological and political education in the courses they are teaching, based on the characteristics of each course and class. As a result, this poses a huge challenge for teachers. Many of the former teaching materials and modes must be renewed or abandoned, and careful thinking is required in order to produce a sensible class design ${ }^{[3]}$. Therefore, teachers should be able to do the following in order to approach curriculum ideological and political education in the right way.

\subsection{Acquiring a thorough understanding of curriculum ideological and political education}

The comprehension of the concept of curriculum ideological and political education is the prerequisite of its effective implementation. With various misconceptions in the way, it is impossible to carry out curriculum ideological and political education in the correct manner. Thus, it is strongly advised that teachers should read the documents and announcements regarding curriculum ideological and political education released by the Chinese Ministry of Education, hold seminars to discuss the files, and learn from online or physical classes that demonstrate the ways to integrate ideological and political education. Everything else follows after a thorough understanding of the notion.

\subsection{Improving ideological and political literacy}

To integrate ideological and political education in their courses, teachers have to become more ideologically and politically aware by acquiring more knowledge in these areas, the systematic understanding of which is still quite rare to the majority. Such knowledge covers a wide range of topics, from the core values of socialist societies, to traditional culture, and laws. Only after understanding what is included in ideological and political education, can teachers better identify the spots in their classes where such knowledge can be incorporated. Again, classes and seminars should be held for teachers to help them digest the knowledge in this area with the highest efficiency. In addition, they can also learn such knowledge from special apps, or television. Above all, a habit of being aware and sensitive to such information is most helpful.

\subsection{Enhancing teachers' ability in class design}

The key to successful curriculum ideological and political education lies in teachers, and the key for teachers to conquer this demanding task is with better 
class design abilities. Due to unique characteristics of each course, teachers most often have to come up with their own design. To accomplish an elaborate design, careful thinking is mandatory. But apart from that, teachers should also be well aware of the teaching methods, aids, and class activities they can use, which requires experience, but most importantly, constant learning. Various online courses and videos can be used to provide inspirations.

\section{Conclusion}

Curriculum ideological and political education is essential, since it defines the new goal in higher education and set the trend for teaching in this new era. To lift the effectiveness of this guideline, above all, we need to clear up the misunderstandings, and comprehend the connotation and denotation of curriculum ideological and political education.

Following that, the paper also listed three tips for teachers with regard to how to approach curriculum ideological and political education in the correct manner, including understanding what is required to do, knowing what should be taught, and how it should be taught. With these efforts, the prevalence and effectiveness of curriculum ideological and political education is expected to be largely increased.

\section{References}

[1] The Chinese Ministry of Education. (2020). Announcement to Publish Guidelines for Curriculum Ideological and Political Education in Higher Education. (Index No. 360A08-07-20200015-1).

Retrieved from http://www.moe.gov.cn/srcsite/A08/ s7056/202006/t20200603_462437.html

[2] Gao DY, Zong AD. From ideological and political theory courses to curriculum ideological and political education: system construction for ideological and political theory courses in universities from a strategic height[J]. Chinese Higher Education, 2017(1): 43-46.

[3] Wei CY. Reform of College English Teaching from the Perspective of Ideological and Political Education[J]. Lifelong Education, 2020, 9(6): 139-141. 